Check for updates

Cite this: RSC Adv., 2017, 7, 25305

Received 17th February 2017

Accepted 24th April 2017

DOI: $10.1039 / c 7 r a 02003 a$

rsc.li/rsc-advances

\section{Effect of textual features and surface properties of activated carbon on the production of hydrogen peroxide from hydroxylamine oxidation}

\author{
Wei Song, (D) * Lin Yu, (D) Xiaowei Xie, Zhifeng Hao, Ming Sun, (D) Hongli Wen \\ and Yongfeng $\mathrm{Li}$
}

\begin{abstract}
Herein, the textural features and surface properties of activated carbon were mediated by oxidation in the gas-phase or liquid-phase. Activated carbon (AC) treated by gas-phase oxidation showed greatly enhanced production of hydrogen peroxide $\left(\mathrm{H}_{2} \mathrm{O}_{2}\right)$ via hydroxylamine oxidation primarily because of the formation of more surface quinoid species. The yield and selectivity of $\mathrm{H}_{2} \mathrm{O}_{2}$ increased to $55 \%$ and $87 \%$, respectively, which were much superior to those of the parent AC catalyst. Detailed structural and surface analyses revealed that gas-phase oxidation produced more quinoid but less carboxylic groups on activated carbon, and the opposite effect was observed for the samples treated by liquid-phase oxidation; this confirmed the crucial role of the quinoid groups on AC. Quantitative correlation of the relationship between the activity and the number of the surface quinoid groups further indicated the critical role of the quinoid groups, serving as intrinsic active species.
\end{abstract}

\section{Introduction}

Hydrogen peroxide $\left(\mathrm{H}_{2} \mathrm{O}_{2}\right)$, an environmentally friendly oxidant, is widely used in chemical industries for textural processes, wastewater treatment, and green chemical synthesis due to its high oxidative efficiency and formation of water as the only byproduct. ${ }^{1}$ With the rapidly increasing stringent legislation and public concerns about the environment, the demand for $\mathrm{H}_{2} \mathrm{O}_{2}$ is experiencing a persistent increase worldwide in the chemical field. However, the current industrial production of this unique green oxidant is accompanied by the generation of large amounts of waste. The well-established alkyl anthraquinone auto-oxidation (AO) process ${ }^{2}$ is actually a multi-step, energy consuming, and waste generating procedure. Additionally, the storage, transport, and handling of $\mathrm{H}_{2} \mathrm{O}_{2}$ in high-concentration increase the cost and safety problems. However, in many oxidative procedures, even a low concentration of $\mathrm{H}_{2} \mathrm{O}_{2}$ can meet the requirement of the reaction..$^{3-6}$ In this context, based on the AO method, the simplification of the production process and its in situ use has attracted significant attention from the researchers. ${ }^{5,7-9}$ The most promising method is the direct production of $\mathrm{H}_{2} \mathrm{O}_{2}$ from molecular oxygen and hydrogen; however, the hazard of this explosive mixture and the lack of selective catalysts have obscured its industrial application to date. ${ }^{\mathbf{1 0 - 1 3}}$

Alternatively, oxidation of suitable hydrogen-containing compounds would be a practical route for the direct

School of Chemical Engineering and Light Industry, Guangdong University of Technology, Guangzhou 510006, PR China. E-mail: songw@gdut.edu.cn; songvvei@ 163.com; Tel: $+86-20-39349149$ production of $\mathrm{H}_{2} \mathrm{O}_{2}$. Hydroxylamine $\left(\mathrm{NH}_{2} \mathrm{OH}\right)$ can be oxidized into $\mathrm{H}_{2} \mathrm{O}_{2}$ by $\mathrm{O}_{2}$ in an aqueous solution under ambient conditions and thus is viewed as a potentially alternative hydrogen resource. ${ }^{14}$ This reaction has been previously shown to have high TOF values using homogeneous manganese complexes as catalysts; ${ }^{15-17}$ however, it suffered from the difficulty of separating and recycling the homogeneous catalyst. Recently, supported noble metal particles, such as Au and Pd, have been reported to effectively catalyze this system; ${ }^{18-20}$ however, the high cost of noble metals and the production of $\mathrm{H}_{2} \mathrm{O}_{2}$ in low concentration (0.05-0.1 wt\%) remain the major obstacles for their industrial applications.

Activated carbon (AC), which is rich in surface functional groups, is attracting extensive attention for use as a catalyst, instead of its conventional role as a support for dispersing metal particles. For example, AC has been applied for the oxidative dehydrogenation of hydrocarbons and dehydrogenation and dehydration of alcohols. ${ }^{21}$ The catalytic performance of ACs is typically assigned to the surface oxygen-containing groups, which are generally created upon oxidation treatments in either a gaseous or liquid phase. The former leads to carbons with a predominant population of quinoid groups, whereas the latter introduces large amounts of surface carboxylic groups. ${ }^{21}$

We have previously found that AC could be a promising catalyst for the direct production of $\mathrm{H}_{2} \mathrm{O}_{2}$ via $\mathrm{NH}_{2} \mathrm{OH}$ oxidation under ambient conditions, ${ }^{22}$ in which the catalytic performance of AC largely depends on the surface oxygen-containing groups, especially the quinoid groups. In this study, we comparatively examined the creation and modification of the surface 
functional groups by treating AC in gaseous and liquid phases with the aim to improve the surface concentration of the quinoid groups. The catalytic activity for the direct production of $\mathrm{H}_{2} \mathrm{O}_{2}$ over the modified AC catalyst correlated well with the number of surface quinoid groups.

\section{Experiments}

\subsection{Surface modification of activated carbon}

Herein, $10 \mathrm{~g}$ activated carbon (200-300 mesh, Aldrich) was initially treated with $100 \mathrm{~mL}$ of concentrated hydrochloric acid $(\mathrm{HCl}, 37 \%)$ to remove the inorganic impurities and ashes. The mixture was stirred at room temperature for $3 \mathrm{~h}$, followed by thorough washing with hot water until the filtrate was free of $\mathrm{Cl}^{-}$ (detected by $\mathrm{AgNO}_{3}$ ). The sample was dried at $110{ }^{\circ} \mathrm{C}$ overnight in vacuum, which was named AC. Then, the AC sample was oxidized with a 5 vol $\% \mathrm{O}_{2} / \mathrm{N}_{2}$ mixture at $425{ }^{\circ} \mathrm{C}$ for $1,3,10$, and $20 \mathrm{~h}$, and the samples were accordingly named AC1, AC3, AC10, and AC20. In the liquid oxidation process, AC ( $3 \mathrm{~g}$ ) was oxidized with $30 \mathrm{~mL}$ of concentrated $\mathrm{H}_{2} \mathrm{SO}_{4}$ at $150{ }^{\circ} \mathrm{C}$ or $3 \mathrm{M} \mathrm{HNO}_{3}$ at $95{ }^{\circ} \mathrm{C}$ for $3 \mathrm{~h}$, or a saturated solution of $\left(\mathrm{NH}_{4}\right)_{2} \mathrm{~S}_{2} \mathrm{O}_{8}$ in $1 \mathrm{M} \mathrm{H}_{2} \mathrm{SO}_{4}$ at room temperature for $24 \mathrm{~h}$. After this, the oxidized AC was thoroughly washed with hot water until the $\mathrm{pH}$ value of the filtrate was nearly neutral, and then, it was dried at $110{ }^{\circ} \mathrm{C}$ overnight in vacuum. The samples thus obtained were named ACS, ACN, and ACP.

\subsection{Characterization of the AC samples}

Nitrogen adsorption-desorption isotherms were obtained using a Micrometrics ASAP 2000 instrument at $-196{ }^{\circ} \mathrm{C}$. Before the measurement, the sample was outgassed overnight at $150{ }^{\circ} \mathrm{C}$. The specific surface area $\left(S_{\mathrm{BET}}\right)$ was calculated via a multipoint Brunauer-Emmett-Teller (BET) analysis.

Chemical titration for the quantitative analysis of acidic groups was based on the Boehm method. ${ }^{23}$ Herein, four series of AC samples $(0.5 \mathrm{~g})$ were first added to four flasks $(150 \mathrm{~mL})$. Then, $50 \mathrm{~mL}$ of $0.05 \mathrm{M}$ sodium hydrogen carbonate $\left(\mathrm{NaHCO}_{3}\right)$, sodium carbonate $\left(\mathrm{Na}_{2} \mathrm{CO}_{3}\right)$, sodium hydroxide $(\mathrm{NaOH})$, and sodium ethoxide $\left(\mathrm{NaOC}_{2} \mathrm{H}_{5}\right)$ were added to the flasks. The flasks were then sealed and stirred at room temperature for $24 \mathrm{~h}$. After recovering the solution via filtration, $10 \mathrm{~mL}$ of aliquots were titrated with $0.05 \mathrm{M}$ of $\mathrm{HCl}$, and the surface oxygenated groups were determined according to the following assumptions. $\mathrm{NaHCO}_{3}$ merely neutralizes carboxyl groups; lactones are determined by the difference between the groups neutralized by $\mathrm{Na}_{2} \mathrm{CO}_{3}$ and $\mathrm{NaHCO}_{3}$; phenols are estimated by the difference between the groups neutralized by $\mathrm{NaOH}$ and $\mathrm{Na}_{2} \mathrm{CO}_{3}$; and carbonyls/quinones are determined by the difference between the groups neutralized by $\mathrm{NaOC}_{2} \mathrm{H}_{5}$ and $\mathrm{NaOH} .^{24}$

The $\mathrm{pH}$ values of the suspension were measured by dispersing $0.4 \mathrm{~g}$ of carbon powder into $20 \mathrm{~mL}$ of water, and the suspensions were stirred overnight to achieve equilibrium.

Fourier transform infrared (FTIR) spectra of the AC samples were obtained via a Bruker Vector 22 spectrometer using a $\mathrm{KBr}$ pellet system containing $0.5 \mathrm{wt} \%$ of AC.

$\mathrm{X}$-ray photoelectron spectroscopy (XPS) measurements were performed via an ESCALAB MK-II spectrometer (VG Scientific
Ltd., UK) using an $\mathrm{Al} \mathrm{K} \alpha$ radiation source with an acceleration voltage of $20 \mathrm{kV}$. The charge effect was corrected by adjusting the binding energy (BE) of C 1s to $285.0 \mathrm{eV}$. The surface atomic ratio of $\mathrm{O} / \mathrm{C}$ was calculated from the peak areas and the sensitivity factors of the elements. ${ }^{25}$

Temperature-programmed desorption (TPD) was conducted using a U-type quartz tubular reactor connected to a quadrupole mass spectrometer (Omnistar, Balzers). The AC sample (40 mg) was loaded and heated to $900{ }^{\circ} \mathrm{C}$ at the rate of $10{ }^{\circ} \mathrm{C} \mathrm{min}{ }^{-1}$ under a helium flow $\left(30 \mathrm{~mL} \mathrm{~min}^{-1}\right)$, and the outlet gas was monitored by the mass spectrometer.

\section{3. $\mathrm{H}_{2} \mathrm{O}_{2}$ production}

The reaction of $\mathrm{O}_{2}$ and $\mathrm{NH}_{2} \mathrm{OH}$ was conducted in a jacketed glass reactor $(100 \mathrm{~mL})$ via stirring under ambient conditions (25 ${ }^{\circ} \mathrm{C}$ and atmospheric pressure), as described elsewhere. ${ }^{22}$ Typically, the reaction mixture contained $0.15 \mathrm{~g}$ of $\mathrm{AC}$ and $1.74 \mathrm{~g}$ $(25 \mathrm{mmol})$ of hydroxylammonium chloride $\left(\mathrm{NH}_{2} \mathrm{OH} \cdot \mathrm{HCl}\right)$ in 50 $\mathrm{mL}$ of water. Before the addition of $\mathrm{AC}$, the $\mathrm{pH}$ value of the $\mathrm{NH}_{2} \mathrm{OH} \cdot \mathrm{HCl}$ aqueous solution was maintained at 8.6 by adding proper amounts of a $1 \mathrm{M} \mathrm{NaOH}$ solution. $\mathrm{O}_{2}\left(25 \mathrm{~mL} \mathrm{~min}^{-1}\right)$ was introduced through a mass flow controller into the reaction medium. Aliquots of the reaction mixture were periodically withdrawn, and the concentration of $\mathrm{H}_{2} \mathrm{O}_{2}$ was analyzed using the colorimetric method based on titanium(Iv) sulphate. ${ }^{26}$ The yield of $\mathrm{H}_{2} \mathrm{O}_{2}$ was calculated on the basis of the reaction stoichiometry $\left(2 \mathrm{NH}_{2} \mathrm{OH}+\mathrm{O}_{2}=\mathrm{N}_{2}+2 \mathrm{H}_{2} \mathrm{O}+\mathrm{H}_{2} \mathrm{O}_{2}\right)$. The concentration of $\mathrm{NH}_{2} \mathrm{OH} \cdot \mathrm{HCl}$ was estimated by the colorimetric method using the ferric complexes of $\mathrm{Fe}(\mathrm{III})-1,10$ phenanthroline. $^{27}$

\section{Results and discussion}

\subsection{Textural features}

Fig. 1 shows the nitrogen adsorption-desorption isotherms and pore size distribution (PSD) of the AC samples. All the AC samples exhibited the characteristics of type I and IV isotherms, indicating the presence of both micropores and mesopores. There were three types of pores on the AC samples: mesopores $(3.3 \pm 0.5 \mathrm{~nm})$, micropores $(1.4 \mathrm{~nm})$, and supermicropores $(0.6$ $\mathrm{nm}) .{ }^{28}$ Minor variations in the pore size and distribution were detected for the samples obtained by gas-phase oxidation, whereas a significant decrease in the pore size was observed for the samples that experienced liquid-phase oxidation. The gasphase treatment did not alter the mesopores and micropores in the samples, whereas the liquid-phase oxidation remarkably decreased the mesopores and micropores, especially for the ACP sample. As shown in Table 1, the total surface area $S_{\mathrm{BET}}$, the mesoporous surface area $S_{\text {mes }}$, and the microporous surface area $\left(S_{\text {mic }}\right)$ were 1729,780 , and $949 \mathrm{~m}^{2} \mathrm{~g}^{-1}$, respectively, for the parent AC. Accordingly, the micropore width $d_{\text {mic }}$, the micropore volume $V_{\text {mic }}$, and the total pore volume $V_{\text {total }}$ were estimated to be $1.87 \mathrm{~nm}, 0.695$, and $1.609 \mathrm{~cm}^{3} \mathrm{~g}^{-1}$, respectively. The values of $S_{\mathrm{BET}}$ and $V_{\text {total }}$ for the AC samples treated by gas-phase oxidation initially increased to $1837 \mathrm{~m}^{2} \mathrm{~g}^{-1}$ and $1.757 \mathrm{~cm}^{3} \mathrm{~g}^{-1}$ for the AC1 sample, whereas slightly decreased to $1441 \mathrm{~m}^{2} \mathrm{~g}^{-1}$ 

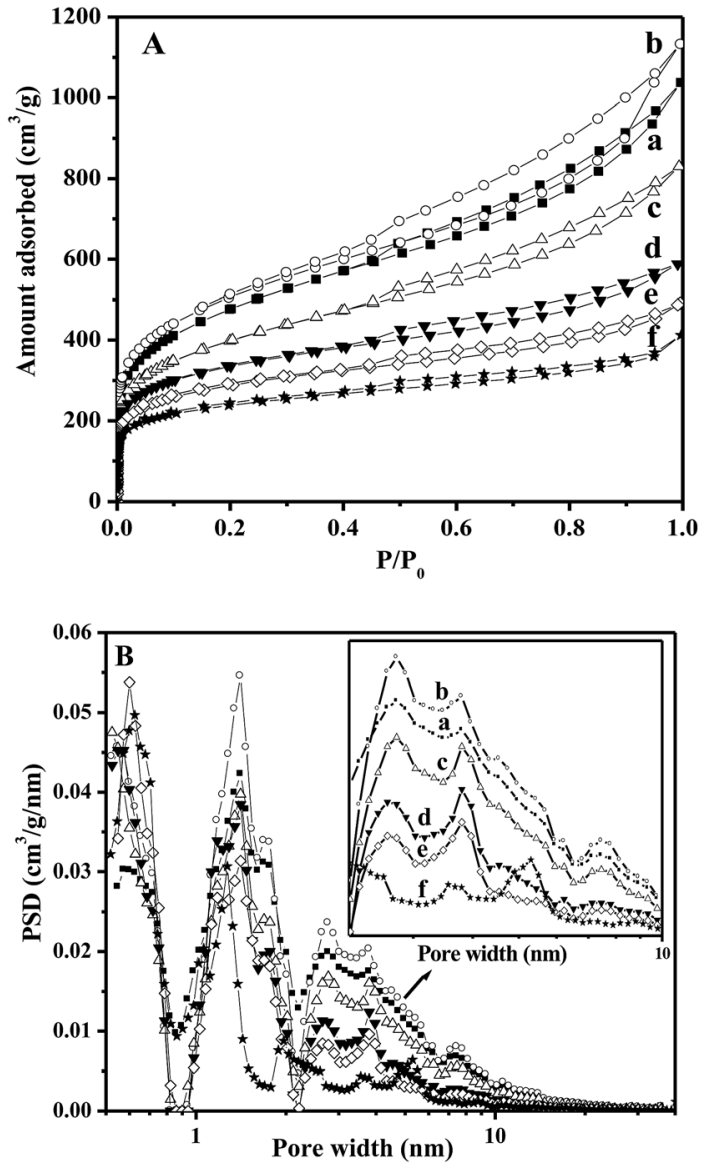

Fig. 1 (A) $\mathrm{N}_{2}$ adsorption-desorption isotherms and (B) pore size distribution by density functional theory method for $A C(a), A C 1$ (b), AC20 (c), ACS (d), ACN (e), and ACP (f) samples.

and $1.287 \mathrm{~cm}^{3} \mathrm{~g}^{-1}$ for the AC20 sample with the increasing treatment time. Moreover, the $d_{\text {mic }}$ for AC samples treated by gas-phase oxidation slightly decreased from 1.87 to $1.73 \mathrm{~nm}$. On the contrary, liquid-phase oxidation resulted in significant changes in the textural parameters. The $S_{\mathrm{BET}}$ of the ACS, ACN, and ACP samples decreased to 1226, 1055, and $879 \mathrm{~m}^{2} \mathrm{~g}^{-1}$, respectively, whereas the corresponding $V_{\text {total }}$ decreased to $0.912,0.762$ and $0.639 \mathrm{~cm}^{3} \mathrm{~g}^{-1}$. In particular, the ACP sample lost nearly three-quarters of its surface area $\left(S_{\text {mes }}\right)$ as compared to the parent AC. This suggests that the liquid-phase oxidation caused severe destruction of the textual structure of AC, whereas the gas-phase oxidation retained the textual feature of the parent AC.

\subsection{Surface properties}

3.2.1. Boehm titration. Table 2 summarizes the results of the Boehm titration and $\mathrm{pH}$ values of the AC samples. As was generally expected, the amounts of all types of surface oxygen groups increased after oxidative treatments, except for the carboxylic groups. In the gas-phase oxidation, by prolonging the time from 1 to $20 \mathrm{~h}$, the amounts of lactonic, phenolic, and carbonylic groups continuously increased, whereas the amount of the carboxylic groups initially decreased to $0.087 \mathrm{mmol} \mathrm{g}^{-1}$ at $3 \mathrm{~h}$ and then increased to $0.470 \mathrm{mmol} \mathrm{g}^{-1}$ at $20 \mathrm{~h}$. In contrast, upon liquid-phase oxidation, the amount of the carboxylic groups significantly increased to 1.085 for ACS, 1.470 for ACN, and $1.526 \mathrm{mmol} \mathrm{g}^{-1}$ for ACP. Moreover, the most pronounced increase in the lactonic groups, phenolic groups, and carbonylic groups was observed for the ACP, ACN, and ACS samples, respectively. Usually, the $\mathrm{pH}$ value of the carbon suspension was related to the overall surface acidity; therefore, it can be simply viewed as an indicator of the degree of oxidation on the carbon surface. As shown in Table 1, oxidative treatment apparently enhanced the total amount of the surface acidic groups. Compared with that of the parent $\mathrm{AC}$ (4.07), the $\mathrm{pH}$ value of the samples treated by gas-phase oxidation only slightly decreased to 3.48 for the $\mathrm{AC} 20$ sample, whereas the $\mathrm{pH}$ value of the samples treated by liquid-phase oxidation significantly lowered to 2.06 for the ACP sample. Consistent with this result, the largest amount $2.451 \mathrm{mmol} \mathrm{g}^{-1}$ of acidic groups was obtained for the AC20 sample treated by gas-phase oxidation, whereas the most abundant acidic groups with an amount of $4.056 \mathrm{mmol}$ $\mathrm{g}^{-1}$ were observed for the ACP sample treated by the liquidphase oxidation. This provided further evidence that the liquid-phase oxidation process generated much more acidic groups on the carbon surface than the gas-phase oxidation process. ${ }^{25}$

3.2.2. FTIR. Fig. 2 shows the FTIR spectra of the AC samples. The band at $1240 \mathrm{~cm}^{-1}$ was ascribed to the $\mathrm{C}-\mathrm{O}$ stretching mold in ethers, lactones, phenols, and carboxylic anhydrides. ${ }^{25}$ The band at $1580 \mathrm{~cm}^{-1}$ was associated with the

Table 1 Textural parameters of the AC samples

\begin{tabular}{|c|c|c|c|c|c|c|}
\hline Catalysts & $S_{\mathrm{BET}}^{a}\left(\mathrm{~m}^{2} \mathrm{~g}^{-1}\right)$ & $S_{\text {mic }}^{b}\left(\mathrm{~m}^{2} \mathrm{~g}^{-1}\right)$ & $S_{\mathrm{mes}}^{b}\left(\mathrm{~m}^{2} \mathrm{~g}^{-1}\right)$ & $V_{\text {mic }}^{b}\left(\mathrm{~cm}^{3} \mathrm{~g}^{-1}\right)$ & $V_{\text {total }}^{c}\left(\mathrm{~cm}^{3} \mathrm{~g}^{-1}\right)$ & $d_{\text {mic }}^{d}(\mathrm{~nm})$ \\
\hline $\mathrm{AC}$ & 1729 & 949 & 780 & 0.445 & 1.609 & 1.87 \\
\hline AC1 & 1837 & 948 & 890 & 0.423 & 1.757 & 1.82 \\
\hline AC10 & 1650 & 810 & 840 & 0.361 & 1.497 & 1.76 \\
\hline $\mathrm{AC} 20$ & 1441 & 703 & 738 & 0.313 & 1.287 & 1.73 \\
\hline ACS & 1226 & 800 & 427 & 0.348 & 0.912 & 1.68 \\
\hline
\end{tabular}

${ }^{a}$ Multipoint BET. ${ }^{b}$ Estimated by the $t$-plot method. ${ }^{c}$ Calculated from the amount of gas adsorbed at the relative pressure of $0.997 .{ }^{d}$ Micropore width calculated via the DR method. 
Table 2 Boehm titration results and $\mathrm{pH}$ values of the $\mathrm{AC}$ samples

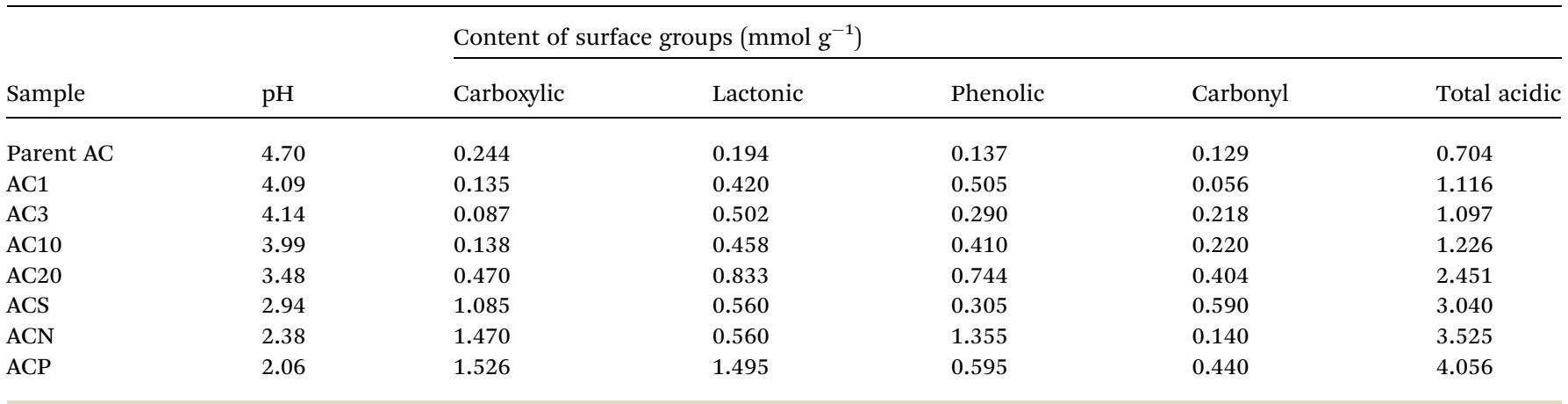

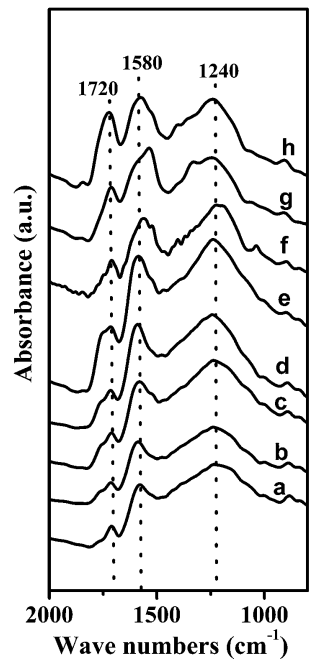

Fig. 2 The IR spectra of $A C$ (a), AC1 (b), AC3 (c), AC10 (d), AC20 (e), ACS (f), ACN (g), and ACP (h) samples.

$\mathrm{C}=\mathrm{C}$ double bond in a quinone-like structure, while the band at $1720 \mathrm{~cm}^{-1}$ was due to the $\mathrm{C}=\mathrm{O}$ stretching vibration from lactones and carboxyl groups in the aromatic rings..$^{29,30}$ Upon oxidation in the gas-phase and liquid-phase, the intensities of these typical bands enhanced to some extent, indicating the generation of large amounts of surface oxygen-containing groups. For the samples obtained by gas-phase oxidation, the increase in the band at $1720 \mathrm{~cm}^{-1}$ was relatively small at the early stages probably because of the partial removal of carboxylic groups from the carbon surface. However, as the gas-phase oxidation was extended to $20 \mathrm{~h}$, the intensities of all the bands remarkably increased, suggesting the creation of more oxygen-containing groups. For the samples obtained by liquidphase oxidation, the bands at 1720,1580 , and $1240 \mathrm{~cm}^{-1}$ were greatly enhanced, suggesting the enrichment with carboxyls, lactones, quinones, and phenols. The most intensive band at $1720 \mathrm{~cm}^{-1}$ was observed for the ACP sample, confirming that the carboxylic groups were further enriched by $\left(\mathrm{NH}_{4}\right)_{2} \mathrm{~S}_{2} \mathrm{O}_{8}$ oxidation. This result is in good agreement with those of the Boehm titrations and $\mathrm{pH}$ values. Thus, it can be concluded that more quinones were generated by gas-phase oxidation, whereas more carboxyls were created by liquidphase oxidation.
3.2.3. XPS. Fig. 3 shows the XPS spectra of $\mathrm{C} 1 \mathrm{~s}$ for the AC samples, and the detailed results of curve fitting are listed in Table 3. The $\mathrm{C} 1 \mathrm{~s}$ spectra consisted of graphitic carbon (Peak I), phenolic, alcohol or ether groups (Peak II), carbonyl or quinone groups (Peak III), carboxyl acidic groups (Peak IV), and a $\pi-\pi^{*}$ shake-up satellite peak (Peak V). ${ }^{31-33}$ The gas-phase oxidation decreased the intensities of the peak I and peak IV, whereas increased the intensities of the peaks ascribed to the carbon-oxygen groups. ${ }^{32}$ Note that the area of peak III initially decreased from $5.4 \%$ to $1.9 \%$ for the AC3 sample and then increased to the maximum value of $7.8 \%$ for the AC20 sample. Moreover, peak IV and peak V were not observed for the AC3 sample, suggesting the removal of the majority of carboxylic groups. This is because of the preferential decomposition of carboxylic groups into $\mathrm{CO}_{2}$ at the early stages. On the other hand, the liquid-phase oxidation merely decreased the intensity of the peak I, whereas it increased the intensities of the doubly bonded carbon-oxygen $(\mathrm{C}=\mathrm{O})$ and carboxylic (-COO-) groups. The area of peak IV of both the ACN (6.8\%) and ACP sample $(7.5 \%)$ was more than two times larger than that of the parent AC $(2.8 \%)$, clearly demonstrating the generation of large amounts of surface oxygen-containing groups, especially the carboxylic groups. However, the areas of peak II for all the AC samples treated by liquid-phase oxidation were much smaller than those for the samples treated by gas-phase oxidation. Additionally, the surface $\mathrm{O} / \mathrm{C}$ atomic ratio for the AC samples treated by liquid-phase oxidation was much more significantly enhanced than that for the samples treated by gas-phase oxidation. These results indicated that more carboxylic and less phenolic groups were produced by liquidphase oxidation, being consistent with Boehm titration and IR measurements.

3.2.4. TPD. Fig. 4 and 5 show the TPD profiles of the AC samples. Upon heating, the surface oxygen-containing groups decomposed into carbon oxides. ${ }^{25,34,35} \mathrm{CO}_{2}$ desorption usually results from the decomposition of carboxylic acids/anhydrides at low temperatures or from the lactones at high temperatures. CO desorption originates from the carboxylic anhydrides, phenols, ethers, carbonyls, and quinones. ${ }^{25}$ Only small amounts of $\mathrm{CO}_{x}$ were detected for the parent $\mathrm{AC}$, whereas considerable amounts of $\mathrm{CO}_{x}$ were detected for the AC samples. For the AC samples prepared by gas-phase oxidation, the amounts of $\mathrm{CO}_{2}$ and $\mathrm{CO}$ gradually increased with the increasing the treatment 

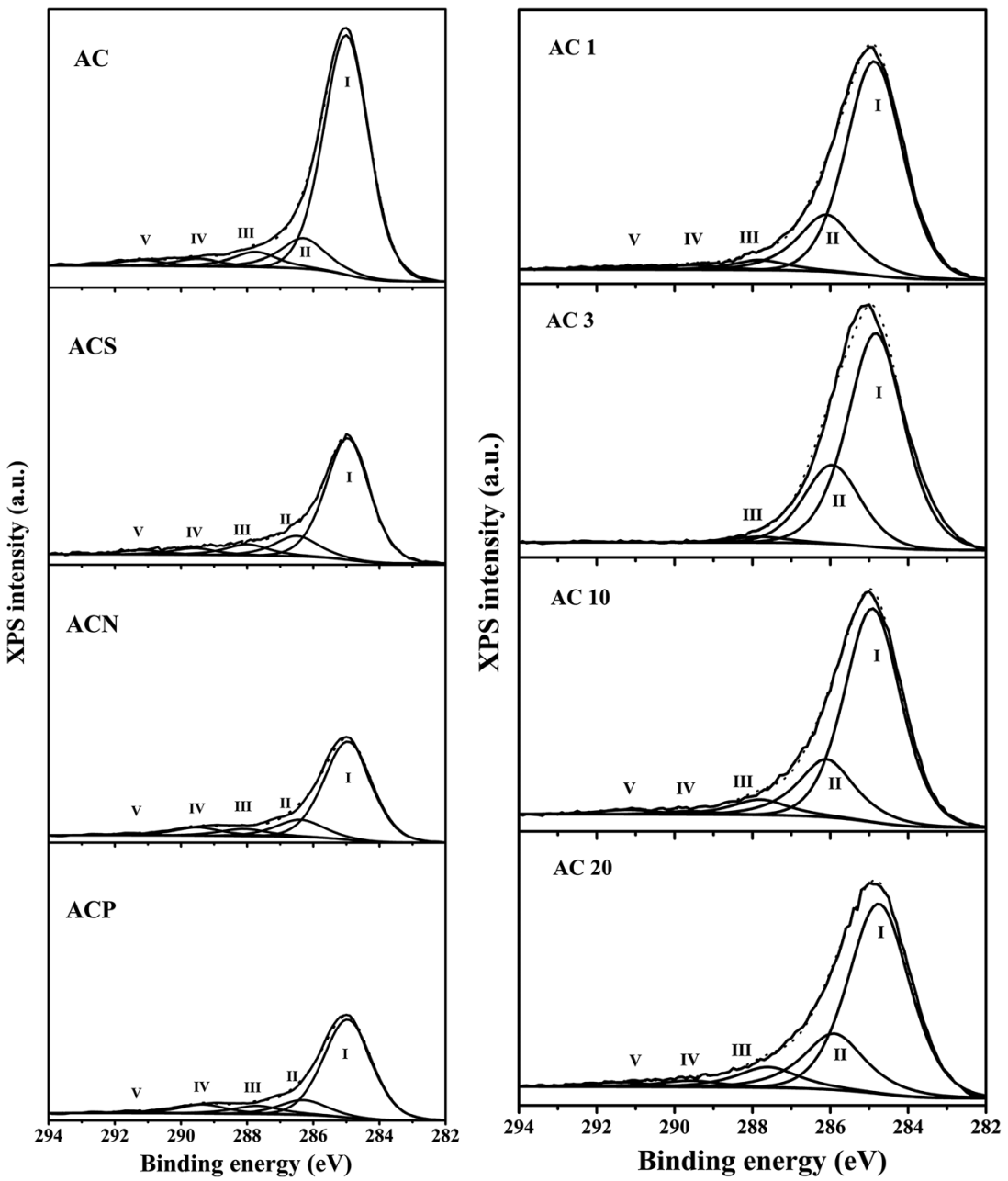

Fig. 3 The XPS spectra of $C$ 1s for the AC samples.

time. Particularly, the amounts of CO desorbed from the AC20 sample were almost four times greater than those of the parent $\mathrm{AC}$, confirming the creation of large amounts of phenolic and carbonyl-quinone groups. On the other hand, the amounts of $\mathrm{CO}_{2}$ desorbed from the samples obtained by liquid-phase oxidation were about two or three times larger than those of the parent AC primarily because of the significant amounts of carboxylic acids/anhydrides and lactones.

Table 4 presents the amounts of specific surface groups. The amounts of $\mathrm{CO}_{2}$ and $\mathrm{CO}$ desorbed from the parent $\mathrm{AC}$ were 598

Table 3 Deconvolution of the C 1s XPS profiles for the AC samples

\begin{tabular}{|c|c|c|c|c|c|c|}
\hline \multirow[b]{4}{*}{ Sample } & \multicolumn{5}{|c|}{ Functional groups/binding energy (ev) } & \multirow[b]{4}{*}{$\mathrm{O} / \mathrm{C}(\%)$} \\
\hline & \multirow{2}{*}{$\frac{\text { Peak I }}{\text { C-graphite }}$} & \multirow{2}{*}{$\frac{\text { Peak II }}{\mathrm{C}-\mathrm{O}}$} & \multirow{2}{*}{$\begin{array}{l}\text { Peak III } \\
\mathrm{C}=\mathrm{O}\end{array}$} & \multirow{2}{*}{$\begin{array}{l}\text { Peak } \\
\text { IV } \\
\text { COO- }\end{array}$} & \multirow{2}{*}{$\frac{\text { Peak V }}{\pi-\pi^{*}}$} & \\
\hline & & & & & & \\
\hline & 284.9-285.0 & $286.3-286.5$ & $287.8-288.1$ & 289.5 & 291.2 & \\
\hline $\mathrm{AC}$ & 78.8 & 10.9 & 5.4 & 2.7 & 2.2 & 7.3 \\
\hline AC1 & 72.7 & 20.8 & 3.6 & 1.7 & 1.2 & 5.3 \\
\hline AC3 & 71.9 & 26.2 & 1.9 & - & - & 5.2 \\
\hline AC10 & 71.0 & 20.7 & 5.5 & 1.1 & 1.7 & 6.7 \\
\hline AC20 & 66.8 & 21.3 & 7.8 & 2.4 & 1.7 & 11.7 \\
\hline ACS & 72.9 & 12.7 & 7.1 & 4.4 & 2.9 & 14.0 \\
\hline $\mathrm{ACN}$ & 73.2 & 13.2 & 5.7 & 6.8 & 1.2 & 22.5 \\
\hline ACP & 73.1 & 11.4 & 6.7 & 7.5 & 1.3 & 25.1 \\
\hline
\end{tabular}




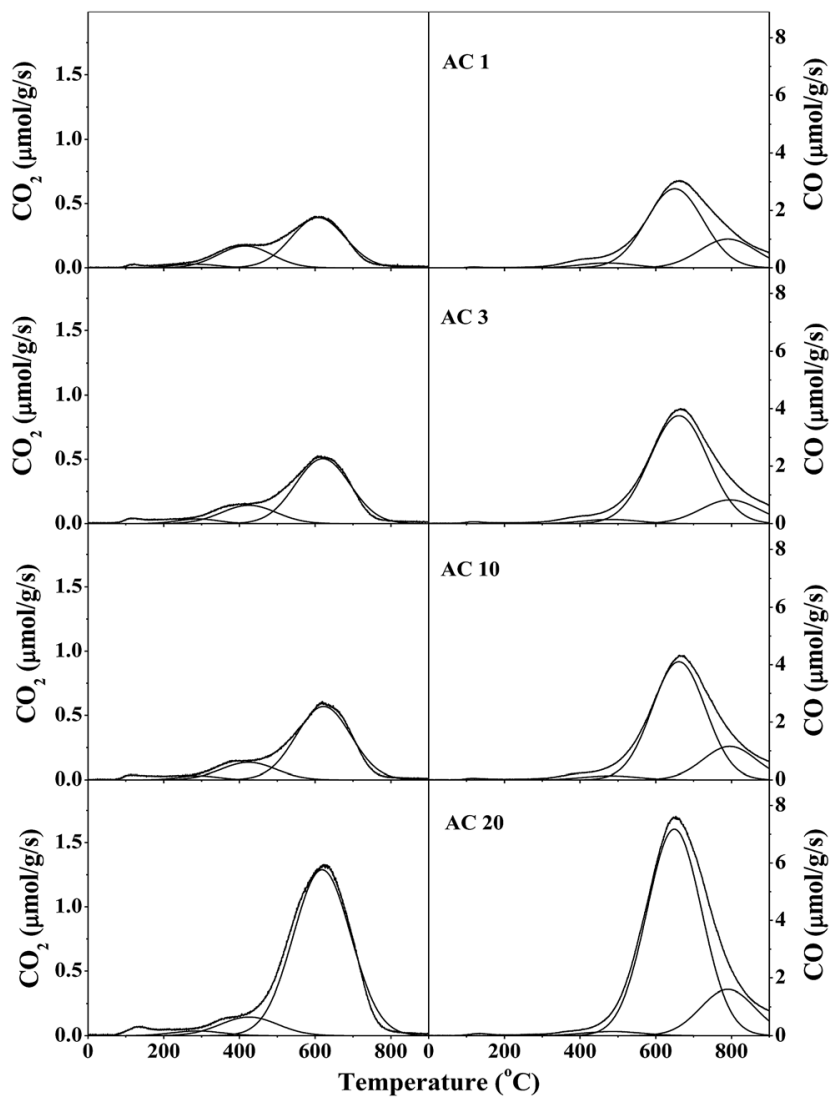

Fig. 4 TPD profiles of AC samples oxidized in gas-phase.

and $3386 \mu \mathrm{mol} \mathrm{g}{ }^{-1}$, respectively, whereas these increased to 1666 and $9688 \mu \mathrm{mol} \mathrm{g}^{-1}$ for the AC20 sample. Upon liquidphase oxidation, the amounts of $\mathrm{CO}_{2}$ and $\mathrm{CO}$ desorbed on the ACP sample were significantly enhanced to 3707 and $6245 \mu \mathrm{mol}$ $\mathrm{g}^{-1}$, respectively. These were similar to those for the ACN sample, but slightly larger than those for the ACS sample. Taking all these observations into account, it can be generally concluded that the largest amount of lactone $\left(1465 \mu \mathrm{mol} \mathrm{g}^{-1}\right)$, phenol $\left(7783 \mu \mathrm{mol} \mathrm{g}^{-1}\right)$, and carbonyl-quinone $\left(1739 \mu \mathrm{mol} \mathrm{g}^{-1}\right)$ groups were obtained for the AC20 sample via gas-phase oxidation, whereas the most enrichment of carboxyl (760 $\left.\mu \mathrm{mol} \mathrm{g}{ }^{-1}\right)$ and anhydride $\left(1910 \mu \mathrm{mol} \mathrm{g}^{-1}\right)$ was detected for the ACP and ACN samples, respectively. In other words, the moderate gas-phase oxidation generated more phenolic groups, whereas the liquid-phase oxidation created more carboxylic groups.

\section{3. $\mathrm{H}_{2} \mathrm{O}_{2}$ production}

Fig. 6 shows the yield of $\mathrm{H}_{2} \mathrm{O}_{2}$ from $\mathrm{NH}_{2} \mathrm{OH}$ oxidation over the AC catalysts. On the parent AC, the yield of $\mathrm{H}_{2} \mathrm{O}_{2}$ remarkably increased during the initial stage and stabilized at around $46 \%$ after reaction for $420 \mathrm{~min}$, followed by a slight decline due to $\mathrm{H}_{2} \mathrm{O}_{2}$ decomposition. Similar reaction patterns were observed for the AC samples prepared by gas-phase oxidation; however, the yield of $\mathrm{H}_{2} \mathrm{O}_{2}$ gradually approached $55 \%$ for the AC20 catalyst. For the AC samples prepared by liquid-phase oxidation, the maximum yield of $\mathrm{H}_{2} \mathrm{O}_{2}$ reached $57 \%$ on ACS catalyst

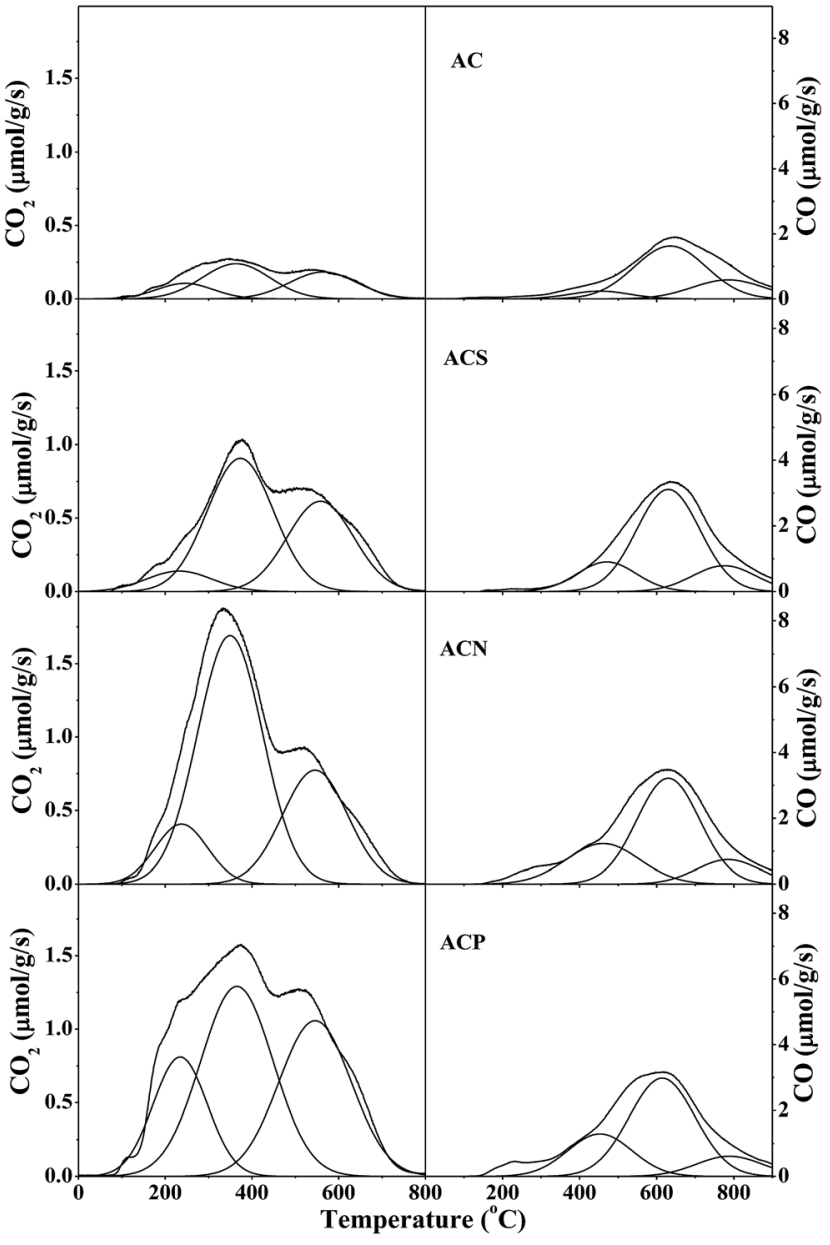

Fig. 5 TPD profiles of AC samples oxidized in liquid-phase.

at 420 min, whereas the yields of $\mathrm{H}_{2} \mathrm{O}_{2}$ for the ACN and ACP samples continuously increased and approached $53 \%$ and $47 \%$, respectively, at $570 \mathrm{~min}$. Fig. 7 shows the comparison of the rate of formation of $\mathrm{H}_{2} \mathrm{O}_{2}$ over the AC catalysts at $60 \mathrm{~min}$. The rate of formation of $\mathrm{H}_{2} \mathrm{O}_{2}$ over the parent AC was $8.8 \mu \mathrm{mol} \mathrm{m}{ }^{-2} \mathrm{~h}^{-1}$, and then, it rapidly decreased because of the consumption of $\mathrm{NH}_{2} \mathrm{OH}$ in the reaction medium. A similar trend was observed for all the AC samples, but the rate of formation of $\mathrm{H}_{2} \mathrm{O}_{2}$ was higher than that of the parent AC. In particular, the rate of formation of $\mathrm{H}_{2} \mathrm{O}_{2}$ was $4.3 \mu \mathrm{mol} \mathrm{m}{ }^{-2} \mathrm{~h}^{-1}$ over the ACS catalyst at $660 \mathrm{~min}$, which was much higher than that over the AC20 catalyst $\left(2.8 \mu \mathrm{mol} \mathrm{m} \mathrm{m}^{-2} \mathrm{~h}^{-1}\right)$, clearly demonstrating the higher initial activity of the AC20 catalyst and more stability of the ACS catalyst.

Fig. 8 shows the conversion of $\mathrm{NH}_{2} \mathrm{OH}$ and the selectivity of $\mathrm{H}_{2} \mathrm{O}_{2}$ over the AC catalysts. Based on the similar conversion of $\mathrm{NH}_{2} \mathrm{OH}(\sim 47 \%)$, the selectivity of the AC catalysts prepared by gas-phase oxidation ranged from 70 to $87 \%$. However, on the AC catalysts obtained by liquid-phase oxidation, the selectivity varied in the range from 66 to $82 \%$. The highest selectivity of $\mathrm{H}_{2} \mathrm{O}_{2}$ was observed on the ACP catalyst, which was possibly induced by the lowest conversion of $23 \%$. Thus, the presence of more reactive quinoid groups on the surface of the AC catalyst 
Table 4 Amounts of desorbed $\mathrm{CO}_{2}$ and $\mathrm{CO}$ on the $\mathrm{AC}$ samples

\begin{tabular}{|c|c|c|c|c|c|c|c|c|}
\hline Sample & \multicolumn{4}{|c|}{$\mathrm{CO}_{2}$ desorption $\left(\mu \mathrm{mol} \mathrm{g}{ }^{-1}\right)$} & \multicolumn{4}{|c|}{ CO desorption $\left(\mu \mathrm{mol} \mathrm{g}^{-1}\right)$} \\
\hline AC1 & 26 & 181 & 415 & 622 & 181 & 3103 & 1128 & 4412 \\
\hline AC3 & 29 & 154 & 547 & 730 & 154 & 4338 & 951 & 5443 \\
\hline AC10 & 24 & 147 & 619 & 790 & 147 & 4342 & 1225 & 5713 \\
\hline $\mathrm{ACN}$ & 368 & 1910 & 875 & 3154 & 1910 & 3953 & 914 & 6778 \\
\hline ACP & 760 & 1620 & 1327 & 3707 & 1620 & 3835 & 790 & 6245 \\
\hline
\end{tabular}

${ }^{a}$ Desorption temperatures: $-290{ }^{\circ} \mathrm{C} .{ }^{b}$ Desorption temperatures: $365-425{ }^{\circ} \mathrm{C} .{ }^{c}$ Desorption temperatures: $565-620{ }^{\circ} \mathrm{C} .{ }^{d}$ Desorption temperatures: $455-490{ }^{\circ} \mathrm{C} .{ }^{e}$ Desorption temperatures: $615-660^{\circ} \mathrm{C} .{ }^{f}$ Desorption temperatures: $785-795{ }^{\circ} \mathrm{C}$.

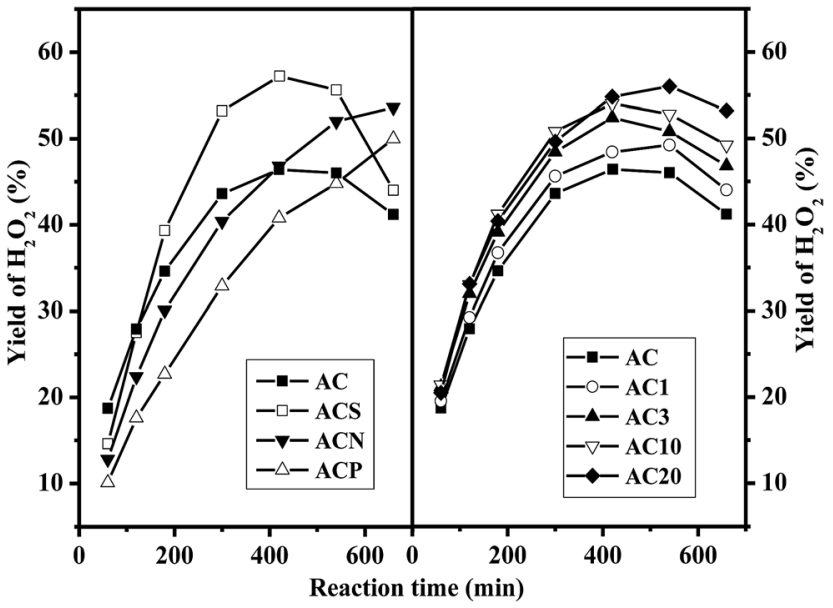

Fig. 6 The yield of $\mathrm{H}_{2} \mathrm{O}_{2}$ over the $\mathrm{AC}$ catalysts (temp. $=25^{\circ} \mathrm{C}, \mathrm{pH}=$ 8.6).

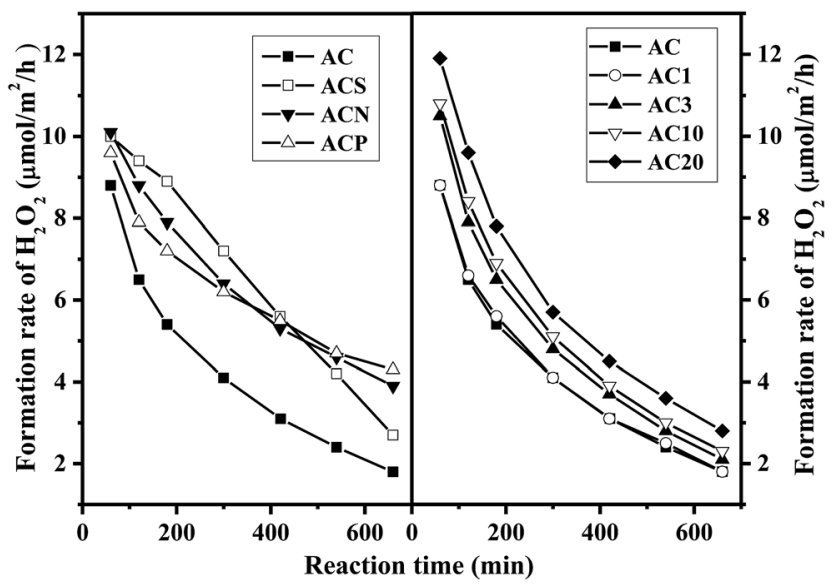

Fig. 7 The rate of formation of $\mathrm{H}_{2} \mathrm{O}_{2}$ over the $\mathrm{AC}$ catalysts (temp. = $25^{\circ} \mathrm{C}, \mathrm{pH}=8.6$ ).

promoted not only the conversion of $\mathrm{NH}_{2} \mathrm{OH}$ but also the selectivity towards $\mathrm{H}_{2} \mathrm{O}_{2}$.

Fig. 9 correlates the rate of formation of $\mathrm{H}_{2} \mathrm{O}_{2}$ with the textural features and the surface functional groups on the $\mathrm{AC}$

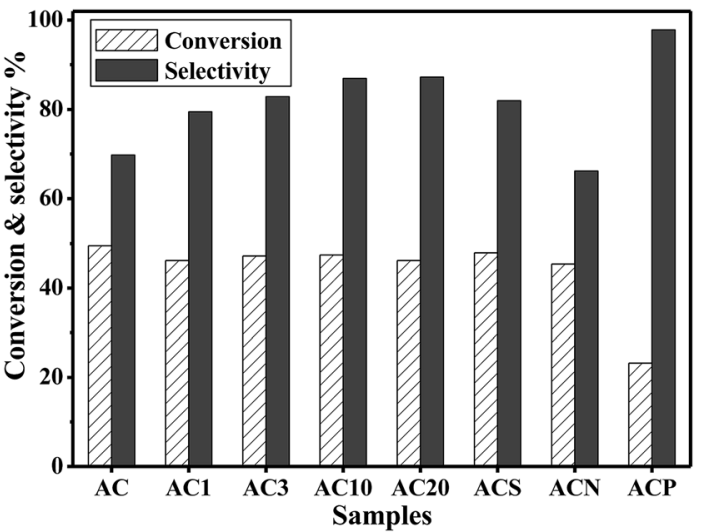

Fig. 8 The conversion of $\mathrm{NH}_{2} \mathrm{OH}$ and the selectivity of $\mathrm{H}_{2} \mathrm{O}_{2}$ over the AC catalysts (temp. $=25^{\circ} \mathrm{C}, \mathrm{pH}=8.6$, and $t=180 \mathrm{~min}$ ).

catalysts. It was obvious that there was no direct correlation between the reaction rate and the surface area, the pore volume or micropore width. That is, the textural parameters did not affect the formation of $\mathrm{H}_{2} \mathrm{O}_{2}$. On the other hand, the correlation between the reaction rate and the surface oxygen-containing groups identified that the rate of formation of $\mathrm{H}_{2} \mathrm{O}_{2}$ almost linearly increased with the increase in the concentration of phenol-quinone groups, whereas the carboxyl-anhydride and/or lactone groups did not alter the reaction rates. Moreover, in our earlier work, ${ }^{22} \mathrm{H}_{2} \mathrm{O}_{2}$ was still generated over the AC catalyst without carboxyl-anhydride groups via thermal treatment at $600{ }^{\circ} \mathrm{C}$, whereas no $\mathrm{H}_{2} \mathrm{O}_{2}$ was detected on the AC surface without phenol and carbonyl-quinone groups via thermal treatment at $800{ }^{\circ} \mathrm{C}$. This further confirmed our previous proposal that the surface oxygen groups, especially the quinoid (phenol and carbonyl-quinone) groups, on the AC catalysts played a crucial role in the production of $\mathrm{H}_{2} \mathrm{O}_{2} \cdot{ }^{22}$ Clearly, the influences of quinoid groups on the rate of formation of $\mathrm{H}_{2} \mathrm{O}_{2}$ were more pronounced.

Additionally, $\mathrm{H}_{2} \mathrm{O}_{2}$ was generated in the homogeneous reaction system with Tiron (1,2-dihydroxybenzene-3,5disulphonate, disodium salt) as the catalyst instead of AC. ${ }^{22}$ These results suggested that the quinoid species were the essential factors governing the catalytic activity of the ACs. To 

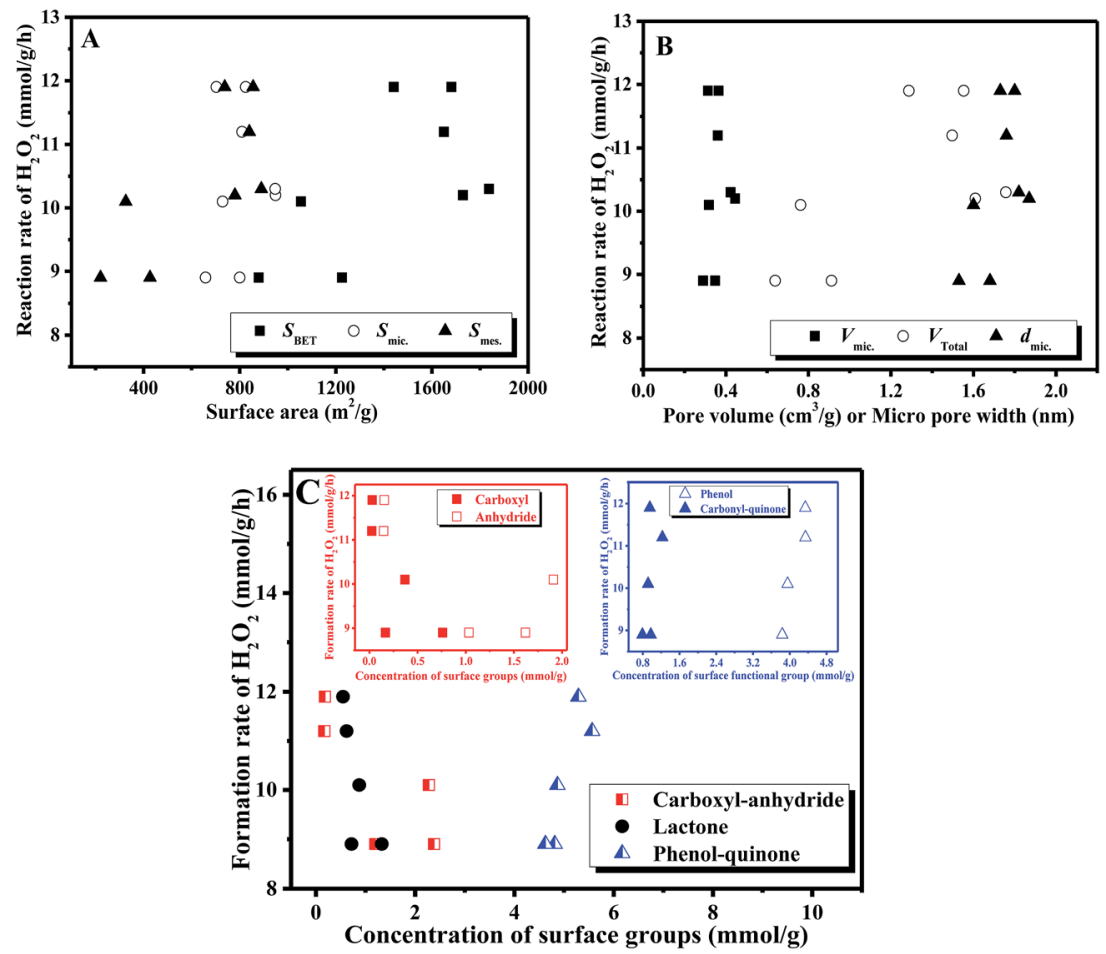

Fig. 9 (A) Catalytic activity versus different types of surface area, (B) pore volume and pore diameter, and (C) different surface functional groups on the $\mathrm{AC}$ catalysts (temp. $=25^{\circ} \mathrm{C}, \mathrm{pH}=8.6$, and $t=30 \mathrm{~min}$ ).

further identify the roles of the oxygen-containing species, a series of homogeneous reactions was performed under the same reaction conditions using the organic compounds containing carboxyl, phenol, quinone, or hydroquinone groups reported in our previous work..$^{36}$ It was found that only Tiron, cyclohexa-2,5-diene-1,4-dione, and hydroquinone provided much higher yields of $\mathrm{H}_{2} \mathrm{O}_{2}$, whereas the $\mathrm{H}_{2} \mathrm{O}_{2}$ yields over benzoic acid, 2-hydroxybenzoic acid, 4-hydroxybenzoic acid, and benzene-1,3-diol were very low. As observed in Fig. 9(C), similar linear slopes between phenol and carbonyl-quinone indicated that phenol groups with hydroquinone structures participated in this reaction as active species. These explanations could be understood by the fact that the pairs of carbonyls at the edges of the carbon layers of a resonance structure behaved as quinones, whereas the pairs of hydroxyls acted as hydroquinones. ${ }^{21}$ Furthermore, the ratio of the rate of formation of $\mathrm{H}_{2} \mathrm{O}_{2}$ /the number of phenol groups, namely turnover frequency (TOF), on different AC catalysts ranged from 2.3 to 2.7 $\mathrm{h}^{-1}$. In general, the surface oxygen-containing groups were considered as the active species in the catalytic reactions when the same TOF value could be obtained on different AC samples.

Therefore, the functional groups on the AC catalysts, particularly the quinoid groups, were the active species in the production of $\mathrm{H}_{2} \mathrm{O}_{2}$. These quinoid species in the carbon materials often serve as electron acceptors and redox mediators, and the quinone-hydroquinone system is usually involved in the redox mechanism. ${ }^{36}$ Herein, the quinonoid species on the ACs received electrons from the reductive substrate $\left(\mathrm{NH}_{2} \mathrm{OH}\right)$ and the reduced species, usually existing in the form of semiquinones or hydroquinones, and channeled the electrons to $\mathrm{O}_{2}$, accomplishing the redox cycle involved in the formation of $\mathrm{H}_{2} \mathrm{O}_{2}$. Hence, the higher performance of the AC20 catalyst could be reasonably and straightforwardly attributed to the surface richness of the quinoid groups.

\section{Conclusions}

Proper tuning of the textural structure and surface chemistry of activated carbons could efficiently promote the production rate of $\mathrm{H}_{2} \mathrm{O}_{2}$ via $\mathrm{NH}_{2} \mathrm{OH}$ oxidation. The textural features and the surface chemical properties of ACs were significantly modified by gas-phase or liquid-phase oxidation. Minor variations in the pore size and PSD were detected for the AC samples obtained by gas-phase oxidation, whereas a significant decrease in the total pore volume was observed for the AC samples obtained by liquid-phase oxidation.

Gas-phase oxidation of activated carbon under mild conditions efficiently enriched the surface quinoid groups, which in turn promoted the yield and selectivity of $\mathrm{H}_{2} \mathrm{O}_{2}$ to $55 \%$ and $87 \%$, respectively, on AC20. This corresponded to a $\mathrm{H}_{2} \mathrm{O}_{2}$ concentration of $0.47 \mathrm{wt} \%$, which was not only much superior to that obtained on the supported noble metals $(0.05-0.1 \mathrm{wt} \%)^{18-20}$ but also comparable to that obtained by the homogeneous manganese complexes catalysts. ${ }^{15-17}$ Liquid-phase oxidation of activated carbon generated more carboxyl groups, lowering the yield of $\mathrm{H}_{2} \mathrm{O}_{2}$. The quantitative correlation between the reaction rate and the number of surface oxygen-containing groups verified that the quinoid groups acted as the active species for $\mathrm{NH}_{2} \mathrm{OH}$ oxidation to $\mathrm{H}_{2} \mathrm{O}_{2}$. 


\section{Acknowledgements}

This work was supported by the National Natural Science Foundation of China $(2160309,51678160)$ and the Startup Foundation for Doctors of Guangdong University of Technology (10313).

\section{References}

1 J. M. Campos-Martin, G. Blanco-Brieva and J. L. G. Fierro, Angew. Chem., Int. Ed., 2006, 45, 6962.

2 G. Goor, W. Kunkel and O. Weiberg, in UllmannCs Encyclopedia of Industrial Chemistry, ed. B. Elvers, S. Hawkins, M. Ravenscroft and G. Schulz, VCH, Weinheim, 1989, vol. A13, pp. 443-466.

3 C. Perego, A. Carati, P. Ingallina, M. A. Mantegazza and G. Bellussi, Appl. Catal., A, 2001, 221, 63.

4 M. G. Clerici and P. Ingallina, Catal. Today, 1998, 41, 351.

5 B. Puértolas, A. K. Hillb, T. García, B. Solson and L. T. Murciano, Catal. Today, 2015, 248, 115.

6 S. Pathan and A. Patel, Appl. Catal., A, 2013, 459, 59.

7 Q. Chen and E. J. Beckman, Green Chem., 2008, 10, 934.

8 J. A. Miller, L. Alexander, D. I. Mori, A. D. Ryabov and T. J. Collins, New J. Chem., 2013, 37, 3488.

9 A. Asghar, A. A. A. Raman and W. M. A. W. Daud, J. Chem. Technol. Biotechnol., 2014, 89, 1466.

10 J. K. Edwards, S. J. Freakley, R. J. Lewis, J. C. Pritchard and G. J. Hutchings, Catal. Today, 2015, 248, 3.

11 J. K. Edwards, S. J. Freakley, A. F. Carley, C. J. Kiely and G. J. Hutchings, Acc. Chem. Res., 2014, 47, 845.

12 Y. Yi, L. Wang, G. Li and H. Guo, Catal. Sci. Technol., 2016, 6, 1593.

13 C. Samanta, Appl. Catal., A, 2008, 350, 133.

14 M. N. Hughes and H. G. Nicklin, J. Chem. Soc. A, 1971, 1, 164. 15 T. S. Sheriff, J. Chem. Soc., Dalton Trans., 1992, 6, 1051-1058. 16 T. S. Sheriff, P. Carr and B. Piggott, Inorg. Chim. Acta, 2003, 348, 115.

17 T. S. Sheriff, P. Carr, S. J. Coles, M. B. Hursthouse, J. Lesin and M. E. Light, Inorg. Chim. Acta, 2004, 357, 2494.
18 V. R. Choudhary, P. Jana and S. K. Bhargava, Catal. Commun., 2007, 8, 811.

19 V. R. Choudhary and P. Jana, Catal. Commun., 2007, 8, 1578. 20 V. R. Choudhary and P. Jana, Appl. Catal., A, 2008, 335, 95.

21 J. L. Figueiredo and M. F. R. Pereira, in Carbon materials for catalysis, ed. P. Serp and J. L. Figueiredo, John Wiley \& Sons, Inc., Hoboken, New Jersey, 2009.

22 W. Song, J. Li, J. Liu and W. Shen, Catal. Commun., 2008, 9, 831.

23 H. P. Boehm, Carbon, 1994, 32, 759.

24 F. J. López-Garzón, M. Domingo-García, M. Pérez-Mendoza, P. M. Alvarez and V. Gómez-Serrano, Langmuir, 2003, 19, 2838.

25 J. L. Figueiredo, M. F. R. Pereira, M. M. A. Freitas and J. J. M. Órfão, Carbon, 1999, 37, 1379.

26 P. A. Clapp, D. F. Evans and T. S. Sheriff, Anal. Chim. Acta, 1989, 218, 331.

27 M. Yang, Huagong Xuebao, 1999, 16, 233.

28 D. Prahas, Y. Kartika, N. Indraswati and S. Ismadji, Chem. Eng. J., 2008, 140, 32.

29 A. Macías-García, M. A. Díaz-Díez, E. M. Cuerda-Correa, M. Olivares-Marín and J. Gañan-Gómez, Appl. Surf. Sci., 2006, 252, 5972.

30 G. de la Puente, J. J. Pis, J. A. Menéndez and P. Grange, J. Anal. Appl. Pyrolysis, 1997, 43, 125.

31 A. P. Terzyk, Colloids Surf., A, 2001, 177, 23.

32 D. V. Brazhnyk, Y. P. Zaitsev, I. V. Bacherikova, V. A. Zazhigalov, J. Stoch and A. Kowal, Appl. Catal., B, 2007, 70, 557.

33 A. Swiatkowski, M. Pakula, S. Biniak and M. Walczyk, Carbon, 2004, 42, 3057.

34 H. P. Boehm, Carbon, 2002, 40, 145.

35 U. Zielke, K. J. Hüttinger and W. P. Hoffman, Carbon, 1996, 34, 983.

36 W. Song, Y. Li, X. Guo, J. Li, X. Huang and W. Shen, J. Mol. Catal. A: Chem., 2010, 328, 53. 